Header for SpringerLink: Lung Cancer (HA Wakelee, Section Editor)

Title:

Treatment of Brain Metastases in Lung Cancer: Strategies to Avoid/Reduce Late Complications of Whole Brain Radiation Therapy

Authors:

Mark G. Shaw, BHB, MBChB, FRANZCR

David L. Ball, MBBS, MD, FRANZCR

Contact Information:

Department of Radiation Oncology, Peter MacCallum Cancer Centre, St Andrews Place, East Melbourne, VIC 3002, Australia.

Phone: +61396561111

Fax: +61396561400

E-mail: mark.shaw@petermac.org

E-mail: david.ball@ petermac.org

Keywords:

Whole brain radiation therapy

Brain metastases

Neurocognitive impairment

Quality of Life

Neuroprotection

Hippocampus 


\section{Opinion Paragraph}

Brain metastases occur in 20-40\% of lung cancer patients. The use of whole brain radiation therapy (WBRT) has been shown to ameliorate many neurological symptoms, facilitate corticosteroid reduction, enhance quality of life (QOL) and prolong survival. The acute and early delayed side effects of WBRT are generally mild and inconsequential whereas late complications are often progressive, irreversible and may have a profound effect on neurocognitive function and QOL. Nevertheless WBRT remains the cornerstone for treatment of multiple brain metastases due to its efficacy and the paucity of other treatment options. In avoidance of WBRT and its potential toxicity, patients of good performance status and $\leq 3$ metastases may be reasonably treated with focal therapy alone (surgery or radiosurgery) without a compromise in survival. In patients with multiple brain metastases and those undergoing prophylactic cranial irradiation (PCI) established methods to mitigate the late complications of WBRT include; total dose observation, dose per fraction restrictions, and avoidance of concomitant chemotherapy. Current areas of active research which hold great potential for benefit include hippocampal sparing radiotherapy and the use of neuroprotective agents.

\section{$\underline{\text { Introduction }}$}

More than 200,000 people are diagnosed with lung cancer each year in the United States [1] . A significant number of these patients will be burdened with cerebral metastases. Various population based, hospital based and autopsy based studies report the incidence of brain metastases in patients with lung cancer to be greater than in any other malignancies. One of the more robust studies, a population based study from the Metropolitan Detroit Area run from 1973 to 2001 revealed 11763 brain metastases in 59038 lung cancer patients - an incidence of $19.9 \%$ [2]. The rate is highest in small cell lung cancer (SCLC) with a Dutch population based study from 1986 to 1995 showing an incidence of $29.7 \%$ with SCLC and $12.6 \%$ with non-small cell lung cancer (NSCLC) [3].

In SCLC in the pre-prophylactic cranial irradiation (PCI) era, an $80 \%$ chance of central nervous system metastases was reported in survivors at 28 months [4]. Within the NSCLC group, brain metastases are more common with adenocarcinomas and large cell carcinomas compared to squamous cell carcinomas [5].

Furthermore, as in other cancers, the incidence of brain metastases is rising due to multiple factors including earlier detection, principally by use of MRI, and longer overall survival as a result of superior local and systemic treatments [6, 7].

Whole Brain Radiation Therapy 
The most frequently used treatment in the management of multiple brain metastases is WBRT. The use of WBRT has been shown to improve many neurological symptoms, allow corticosteroid reduction, enhance quality of life (QOL) and prolong survival.

Untreated, patients with brain metastases have a dismal prognosis with an estimated median survival of only a month [8]. Corticosteroids and anticonvulsants offer symptomatic benefit but median survival with corticosteroids alone does not exceed 2 months $[9,8]$. Non-randomised studies suggest WBRT increases median survival to 3-6 months $[9,8]$.

Despite its benefits, WBRT is ultimately a palliative measure and the modest doses used are effectively sub-therapeutic for eradication of clinically evident disease. Higher doses are limited by the risk of normal tissue morbidity and perceived futility in the presence of uncontrolled extracranial disease.

\section{Complications of WBRT}

The complications from WBRT have generally been divided into three categories, divided according to time - acute, early delayed and late delayed [10, 11].

Acute reactions, which are generally mild and inconsequential, occur during or within a few weeks of radiotherapy. They are often due to an exacerbation of peritumoural oedema and include fatigue, headache, nausea and alopecia. Early delayed reactions occur typically $\leq$ six months after radiotherapy and include somnolence syndrome, short-term memory loss and acute leukoencephalopathy. Late delayed complications after WBRT create the greatest concern in patients and physicians. The onset is usually > six months after radiotherapy, is generally irreversible, progressive and may be fatal $[10,11]$. Such complications may include radionecrosis, vascular injury and demyelination. Neurocognitive impairment can result from any of these but may also be identified in the absence of radiographically visible anatomical injuries [12].

There is a wide spectrum of neurological impairments described from the most severe, overt dementia, through to variable decline in memory, mood, concentration, attention and executive function.

Radiation induced dementia is uncommon. DeAngelis et al reported on dementia in groups of patients cured of brain metastases and described an overall 1.9-5.1\% rate of dementia post radiotherapy. The most at risk patients were those who received high fractional doses ( $>3 \mathrm{~Gy}$ ), had concurrent chemotherapy and survived $\geq$ one year [13]. Milder neurological impairment, however, is detectable in the majority of patients treated with radiotherapy and its prevalence increases with time [14, 12, 15].

Studies attempting to assess impairment in neurocognitive function (NCF) are often difficult to compare as numerous definitions of neurological impairment are used, function is measured at different time points and a variety of assessment techniques are employed, including patient self-reporting, clinician observation, Mini Mental State Examination (MMSE) or a battery of neurological tests [16, 15]. The MMSE has been most frequently used but its weaknesses are well documented [17]. Trials in the current era tend to use a battery of neurocognitive tests to better detect and 
quantify neurocognitive impairment. QOL has not been extensively studied in patients with brain metastases despite the fact that neurocognitive impairment has a significant impact on QOL $[18,19]$.

A recent review set out to determine the average incidence, magnitude and time to occurrence of radiation induced neurocognitive decline following WBRT [20]. The authors concluded that neurocognitive decline peaked at four months post WBRT, severity was usually mild (only $8 \% \geq$ grade 2 on the SOMA-LENT scale) and thereafter marginal improvements were seen in NCF before a late decline in a biphasic pattern. NCF was directly related to control of brain metastases, that is, patients with uncontrolled cerebral disease exhibited the worst neurocognitive impairment. This last finding has been supported by multiple studies $[14,21]$ and is one of many factors that creates uncertainty when evaluating the impact of radiotherapy on neurological function. Furthermore a significant proportion of patients have neurocognitive impairment at baseline even without brain metastases $[16,22,23]$. Neurocognitive deterioration may also be attributed to other oncological treatments including chemotherapy, hormonal therapy, neurosurgical intervention, anticonvulsants, corticosteroids and opiods [24-27]. Fatigue, depression and medical co-morbidities may also be contributing factors. Furthermore, the combination of these therapies and co-morbidities with radiotherapy increases the risk of neurocognitive impairment beyond that of radiotherapy alone $[28,29]$.

\section{$\underline{\text { Mechanism of injury }}$}

The mechanism of radiation induced injury which leads to late effects in the brain is not clearly established and is almost certainly multifactorial. The classical hypothesis of clonogenic cell death of endothelial cells and glial cells cannot feasibly explain many of the changes identified with radiation induced injury - particularly neurocognitive impairment. The current popular hypothesis is that of a dynamic interplay between multiple cell types within the central nervous system which is ultimately responsible for clinical neurocognitive decline [30, 11, 31].

\section{TREATMENT}

\section{Dose-Fractionation Reduction in Prophylactic Cranial Irradiation (PCI)}

The role of PCI and its impact on NCF has been studied in phase III randomised trials in both SCLC [32, 22] and NSCLC [33]. Gregor et al found ongoing NCF decline at 6 months and 1 year in both the PCI and observation groups but no significant difference between the two [22]. Arrigada et al also found no significance difference in NCF impairment between the PCI and observation groups over 2 years [32]. The more recent study by Sun et al found a statistically significant greater decline in Hopkins Verbal Learning Test (HVTL) immediate recall and delayed recall at one year in the PCI arm, but with no change in MMSE, QOL or Activities of Daily Living Scores it is difficult to assess the clinical relevance, if any of this change [33]. 
Compared with therapeutic cranial irradiation (brain metastases present), PCI appears to be associated with milder/less frequent NCF decline. This may be partially attributable to the lower total doses or doses per fraction generally used. In patients treated with PCI on the PCI99-01 study, a randomised controlled trial (RCT) of 25Gy versus 36Gy for limited stage SCLC, the authors found deterioration over time with communication, weakness in legs, intellectual deficit and memory without difference between dose groups [34]. The RTOG 0212 trial examined the effect of PCI dose and fractionation on chronic neurotoxicity and QOL in 264 patients, of which 146 were co-enrolled in the PCI99-01 trial [35]. Unlike the PCI99-01 trial they used a battery of neurocognitive tests and revealed a significantly greater degree of neurocognitive deterioration with $36 \mathrm{~Gy}$ compared to $25 \mathrm{~Gy}$ ( $85-89 \%$ versus $62 \%$ at one year). Both higher dose and age were statistically significant factors for developing chronic neurotoxicity. Greater dose per fraction and the use of concomitant chemotherapy during PCI also appear to be associated with increased risk of neurotoxicity [36].

\section{Impact of dose/fractionation schedules}

A Cochrane review of WBRT dose fractionation schemes did not show a benefit in neurological function with altered fractionation regimes compared to standard doses of 30Gy/10\#, 20Gy/4\# or 20Gy/5\#) [37]. Hypofractionated regimes, however, have proven hazardous with significant acute complications. Regimes of $15 \mathrm{~Gy}$ in 2 fractions [38] and 10Gy in one fraction [39] have both recorded radiation induced deaths in the acute phase.

\section{Hippocampal sparing radiotherapy}

Mitotically active neural stem cells (NSC) are located in two sites within the brain, the subgranular zone (SGZ) located within the dentate gyrus, and the subventricular zone (SVZ) on the lateral aspect of the lateral ventricle. NSC within the SGZ give rise to new hippocampal cells which, throughout adult life, migrate into the granular cell layer of the hippocampus [40]. Dentate gyrus granule cells are thought to have a function in learning and memory, particularly spatial memory [41]. There exists significant preclinical evidence that radiation induced injury to the hippocampus correlates with neurocognitive decline. Furthermore, in rodents, it appears that the NSC in the SGZ of the hippocampi may be the sensitive targets responsible for this decline $[42,43]$.

The concept of hippocampal sparing radiotherapy arose on the basis of this preclinical research combined with the fact that neurocognitive deficits following radiotherapy correlate with hippocampal dependent functions of memory, learning and spatial processing. Sparing the hippocampus should be safe as it is seldom involved with metastases. Wan et al examined 2270 metastases in 488 patients showing a 1.1\% involvement by metastases in either NSC regions [44]. Gondi et al have shown no hippocampal metastases of 1133 metastases in 371 patients, but reported metastases within $5 \mathrm{~mm}$ of the hippocampus in $8.6 \%$ of patients [45]. This $5 \mathrm{~mm}$ perihippocampal region is stipulated as the avoidance target in the RTOG contouring guidelines [46] (figure 1). Gondi et al, using the RTOG contouring guidelines to define the hippocampus, have shown a correlation between hippocampal dose and 
neurocognitive impairment in patients with low grade glioma with a bilateral hippocampal D40\% > 7.3Gy correlated with memory impairment [47].

The RTOG have completed accrual on a phase II trial examining the impact of hippocampal sparing WBRT on neurocognition and QOL (RTOG 0933). Participants were treated to a dose of 30Gy/10\# with Tomotherapy or IMRT with the protocol stipulating a hippocampal D100\% of $\leq 9$ Gy with a maximum dose $\leq 16 \mathrm{~Gy}$. Accrual was reached and closed in July 2012 and its primary objectives are, as yet unreported. The investigators have published limited data demonstrating, for a prescribed dose of 30Gy/10\#, that hippocampal dose can be reduced to a median of 5.5Gy using helical Tomotherapy or 7.8Gy using LINAC based IMRT [45]. Indeed these low dose levels may be required due to the exquisite sensitivity of the neural stem cells [48].

Whilst these techniques are interesting and may yield beneficial outcomes it seems implausible that NCF is entirely dependent on the hippocampal function alone. In fact some propose that both NSC populations (SGZ and SVZ) or the entire limbic circuit should be spared and have shown that it can feasibly be performed [49-51].

Insert figure here

Fig.1 Right hippocampus with 5mm PTV margin contoured on axial, coronal and sagittal MRI images according to the RTOG 0933 Protocol [46]

\section{Surgery or Radiosurgery alone (withholding WBRT)}

There is limited role for local therapy in patients with diffuse cerebral metastases beyond surgical management of a dominant symptomatic lesion. In patients with limited cranial metastases however there has been significant interest in finding a group who may benefit from local therapy alone thus avoiding any potential WBRT related toxicity [52]. RCT have suggested that local therapy alone (SRS or surgery) for $\leq$ three brain metastases whilst associated with poorer intracranial control of disease, does not compromise overall survival [53-56]. These studies also assessed neurological, neurocognitive or functional endpoints.

Aoyama et al reported on a phase III RCT of 132 patients with $\leq$ four brain metastases randomised to SRS alone or SRS with WBRT (30Gy in 10 fractions) [53]. The primary endpoint was median survival and included amongst the secondary endpoints were KPS at one year, incidence of neurological death and MMSE score - none of which was significantly different between the arms.

Chang et al have published the only phase III RCT of SRS alone versus SRS plus WBRT (30Gy in 12 fractions) with NCF as the primary endpoint [54]. NCF was assessed with a battery of tests. The study was closed early after accrual of 58 patients when the data monitoring committee found a significant decline in HVLT-R measured learning and memory function at 4 months in the SRS plus WBRT arm $(52 \%)$ versus the SRS alone arm $(24 \%)$. Strikingly the survival was significantly longer in the SRS alone arm (15.2 months versus 5.7 months; $\mathrm{p}=0.003)$, despite a higher rate of CNS recurrence at one year (73\% versus $27 \%$; $\mathrm{p}=0.0003)$. The authors 
concluded that the study provided "Level 1 evidence to support the use of SRS alone in the initial management of patients newly diagnosed with one to three brain metastases".

The validity of that conclusion was considered somewhat controversial, and drew criticism from observers $[57,58]$ who cited methodological flaws and inconsistencies with the results of other RCT showing equivalent survival in those receiving WBRT $[53,55,56]$.

The European Organisation for Research and Treatment of Cancer (EORTC) compared 359 patients of WHO performance status (PS) 0-2 with $\leq$ three brain metastases in a phase III RCT of local therapy (surgery or SRS) alone or in combination with WBRT (30Gy in 10 fractions) [55]. Overall survival and median time to WHO PS $>2$ were similar in both arms. Salvage therapies were used more often in the observation arm and intracranial progression as a cause of death was more frequent in the observation arm (44\%) than in the WBRT arm (28\%). No dedicated NCF testing was performed but Health Related Quality of Life (HRQOL) was a secondary endpoint. In summary patients in the observation arm scored higher HRQOL scores with significant differences found in a few, transitory areas (fatigue and physical functioning at 8 weeks, global health status at 9 months and cognitive functioning at 12 months) [59]. The authors' conclusion was that observation after surgery/SRS and close monitoring with MRI is reasonable in well-performing patients with stable systemic disease and $\leq 3$ brain metastases, and is not detrimental to HRQOL.

This remains a controversial area particularly as intracranial control, which is where the addition of WBRT is most effective, has been shown to correlate with maintenance of NCF and QOL [14, 60, 21]. On balance however it appears reasonable to consider SRS alone and close monitoring for patients with $\leq 3$ brain metastases.

\section{Neuroprotectors}

\section{$\underline{\text { Memantine }}$}

Vascular injury following radiation therapy is well recognised $[30,11]$ and its pathogenesis has similar mechanisms to those underlying vascular dementia [61]. Medications that have proven beneficial in improving neurocognitive function in vascular dementia have thus been considered for a role in preventing neurocognitive impairment following cerebral irradiation.

Memantine is a N-methyl-D-aspartate (NMDA) receptor antagonist with proven efficacy in vascular and Alzheimer's dementia [62]. Under basal conditions the neurotransmitter glutamate binds with the NMDA receptor and through this action is involved with synaptic plasticity and consequentially memory [63]. Following ischaemic insults, an increase in glutamate levels can rapidly occur giving rise to a 'gluatamatergic storm' which causes excessive NMDA receptor stimulation and subsequent cell death (excitotoxicity). 
The RTOG examined the potential of memantine in preventing cognitive dysfunction in patients receiving WBRT in a RCT - RTOG 0614. This is yet to be published but was presented in abstract form at ASTRO 2012 [64]. Patients received WBRT (37.5Gy in 15 fractions) and were randomised to receive placebo or memantine, $20 \mathrm{mg} / \mathrm{day}$, within three days of initiating radiation therapy, for 24 weeks. The primary endpoint was memory decline as measured with the HVLT-R Delayed Recall (HVLT-R DL) at 24 weeks. 554 patients were accrued of whom 508 were eligible. When comparing patients in the two arms, patient and treatment characteristics were well balanced and study compliance was similar. Only $32 \%$ of the patients completed the drug therapy per protocol mainly due to a poorer than expected survival and progressive disease which led to non-compliance. No differences in overall survival or progression free survival were seen between the arms. Concerning the primary endpoint, there was less decline on the HVLT-R DR in the memantine arm (median decline of 0 ) compared to the placebo arm (median decline of -2) at 24 weeks $(p=0.059)$. Although this was not statistically significant, memantine was shown to delay time to cognitive decline $(\mathrm{p}=0.02)$ and patients in the memantine arm experienced a $17 \%$ relative reduction in cognitive decline at 24 weeks compared to those in the placebo group $(p=0.01)$. The final publication is eagerly awaited before a conclusive recommendation can be made regarding the use of memantine after WBRT for brain metastases.

\section{Donepezil}

Donepezil, an acetyl cholinesterase inhibitor, is used to treat mild to moderate dementia in Alzheimer's disease. Donepezil delays the breakdown of acetylcholine in synaptic clefts and by doing so enhances cholinergic neurotransmission, which is associated with memory. Donepezil administration for 24 weeks, in a group of patients with primary brain tumours who had survived $\geq 6$ months post radiation, was shown to improve cognitive function, mood and health related QOL [65]. Based on these positive findings a randomised phase III, placebo controlled, double blinded trial of donepezil and partial or whole brain radiotherapy was conducted, completed and presented in abstract form at ASCO 2013 [66].

In this study 198 adult survivors of primary and metastatic brain tumours, who completed cerebral irradiation to $\geq 30 \mathrm{~Gy}$ at least 6 months prior to enrolment, were randomly assigned to receive 24 weeks of Donepezil 5-10mg per day or placebo. Cognitive function was assessed at baseline, 12 and 24 weeks with a battery of neuropsychological tests with a Cognitive Composite (CC) score as the primary outcome. $74 \%$ of participants completed the study. The CC score improved significantly by 24 weeks in both arms $(p<0.01)$ however, there was not a statistically significant difference between the groups $(p=0.57)$. The donepezil group performed better than placebo on HVLT Recognition $(\mathrm{p}=0.03)$, Discrimination $(\mathrm{p}=0.01)$ and GPDominant Hand $(\mathrm{p}=0.02)$. Statistically significant interactions were found between the treatment arm and baseline cognitive scores for several test components and in all cases the benefit of Donepezil, relative to placebo, was greater for those with worse baseline scores. The authors concluded that there may be a role for donepezil in the treatment of long-term cerebral radiotherapy survivors who have cognitive impairment, particularly in verbal memory, working memory, visuomotor and psychomotor performance and executive functioning. The final publication is awaited. 
The appeal of pharmaceutical agents that can recover lost neurocognitive function is attractive in that it avoids the potential toxicity and side effects of taking a mitigating agent in patients who are destined to early relapse and short survival, where neurocognitive decline may not become a concern.

\section{$\underline{\text { Lithium }}$}

Lithium carbonate is used as a mood stabiliser primarily in the treatment of bipolar disorder. Recently it has been shown to have neuroprotective effects with regard to a wide range of cerebral insults including ischaemia, neurodegeneration, neuroinflammation and radiation [67-70]. Patients with bipolar disorder treated with lithium for 4 weeks show an increase in brain grey matter and hippocampal volume as identified on MRI imaging [71]. Various animal studies have demonstrated the positive effect of lithium on the hippocampus, including rodent studies which have shown that under normal conditions, without cerebral insult, lithium administration can enhance hippocampal neurogenesis [72], and that lithium protects irradiated hippocampal neural progenitor cells from apoptosis, translating to improved cognitive performance $[73,69]$. It is reasonable to hypothesise that the neuroprotective benefits seen in ameliorating the cognitive loss with irradiation in animal studies may translate to benefits in humans.

The direct mechanism of lithium's neuroprotection is unclear, but potentially its major neuroprotective actions come from its inhibition of glycogen synthase kinase 3 beta, activation of Akt, suppression of p53 and Bax expression and increase in Bcl-2 expression [69].

Our institution is involved in a feasibility study of lithium use with prophylactic cranial irradiation for patients with small cell lung cancer. Radiotherapy will be prescribed at $25 \mathrm{~Gy}$ in 10 fractions and patients will be randomised to receive either lithium (at a blood plasma range of 0.4 to $0.8 \mathrm{mmol} / \mathrm{L}, 1000-2500 \mathrm{mg} /$ day) or placebo. Lithium will be administered for 6 weeks commencing one week after the end of radiotherapy. Cognitive impairment will be assessed via a battery of neurocognitive tests. The study feasibility will be measured by successful accrual, safety and randomisation tolerability [74].

\section{$\underline{\text { Renin Angiotensin System (RAS) Blockers }}$}

The RAS is recognised as having localised effects within organs as well as its systemic role in blood pressure and fluid balance regulation. The local brain RAS system is complex and involved in blood pressure regulation, fluid and food intake, temperature regulation, motor control, maintenance of the blood brain barrier, learning, memory, behaviour and emotions [75]. RAS may be involved with the chain of events leading to radiation induced injury as blockade of the RAS in irradiated rats has been shown to have mitigating effects on radiation injury in both kidney and lung [76, 77]. 
Pharmacological agents available that interrupt the RAS at different points include Angiotensin Converting Enzyme Inhibitors (ACEI) and Angiotensin II type 1 receptor Blockers (ARB). RAS blockers are attractive drugs for translational clinical trials as they are commonly used, have an established side effect profile, are well tolerated, show positive results in preclinical trials and might enhance cancer therapies [78, 79]. The first proof of benefit was shown by Kim et al who administered ramipril for six months to rats treated stereotactically to the brain with 30Gy. Using a wellcharacterised optic neuropathy model the authors showed profound reduction in the demyelination of optic nerves and reduced severity of visual injury with chronic ramipril usage [80]. The administration of the ARB L-158,809 to rats 3 days prior through to 5, 26 or 52 weeks after WBRT to 40Gy ( 2 x 5Gy per week for four weeks) prevented or ameliorated radiation induced cognitive impairment [81].

Although both ACEI and ARB have demonstrated activity in modulating radiation induced brain injury, the exact mechanism of their action is not well understood. The initial presumption that RAS blockers worked through a reduction in neuroinflammation appears inadequate or incomplete. Conner et al administered L158,809 to rats before and after a single 10Gy fraction to the brain. Despite reducing cognitive deficits there was no reduction in the neuroinflammatory microglial response or impairment of neurogenesis [82]. This is in contrast to the results reported by Lee et al who administered ramipril to rats before and after fractionated WBRT and noted a reduction in microglial activation in the dentate gyrus [83]. Radiation induced impairment of dentate gyrus neurogenesis was mitigated following administration of atorvastatin (a statin) and ramipril in combination, before and after WBRT [84]. Other possible mechanisms of action of RAS blockers involve an alteration in the balance from angiotensin II to Angiotensin-(1-7), which limits inflammation and oxidative stress, and inhibition of nicotinamide adenosine dinucleotide phosphate oxidase-mediated oxidative stress inflammation [79].

\section{$\underline{\text { Perioxisomal proliferator-activated receptor (PPAR) agonists }}$}

PPAR agonists are ligand activated transcription factors of the nuclear hormone receptor superfamily. PPAR agonists have been trialled successfully in several CNS injuries and diseases to decrease neuroinflammation with the goal of limiting injury [85]. Fenofibrate, a PPAR $\alpha$ agonist, is used as a cholesterol lowering agent often in combination with a statin. Ramanan et al studied the impact of fenofibrate on preserving hippocampal neurogenesis in mice after WBRT and found that the PPAR $\alpha$ agonist both preserved hippocampal neurogenesis and inhibited microglial activation [86]. A subsequent study, however, on the PPAR $\delta$ agonist GW0742 administered to mice irradiated with a single 10Gy WBRT dose prevented an increase in inflammatory markers and hippocampal microglial activation but did not rescue neurogenesis or prevent early delayed hippocampal dependent neurocognitive impairment [87]. Pioglitazone, a PPAR $\gamma$ agonist, administered before, during and post radiation prevented radiation-induced cognitive impairment in young adult male rats, but starting Pioglitazone after radiation did not significantly reduce radiationinduced cognitive impairment [88].

These studies suggest that PPAR agonists may ameliorate radiation induced cognitive impairment and may do so independent of any impact on neurogenesis. Researchers 
at Wake Forest Baptist Medical Centre have championed the investigation into PPAR agonists and a clinical phase I/II study of pioglitazone for the prevention of radiation induced cognitive dysfunction is currently recruiting [89].

\section{Other Investigational Agents}

Many other agents have been or are currently being investigated for potential activity in reducing the impact of cerebral irradiation on neurocognitive function. Some of the more recent publications have explored the use of fingolimod [90]; estrogens [91]; minocycline [92]; baicalein [93]; statins [84]; ginkgo biloba [94]; hesperidin [95]; dragons blood (the plant resin Dracaena cochinchinensis) [96] and tamoxifen [97].

Perhaps one of the most intriguing findings was by Wong-Goodrich et al who found that daily running (by introducing a running wheel into the rat cage) following WBI prevented the marked decline in spatial memory retention observed months after irradiation [98]. Their findings suggest exercise may have a role in ameliorating radiation induced cognitive decline.

\section{Neural Stem cell Transplantation}

The promise of renewal by stem cell transplantation has been explored.

Transplantation of human embryonic stem cells into the hippocampal formation of athymic nude rats 2 days after cranial irradiation (10Gy) ameliorated radiation induced hippocampal dependent cognitive impairment at four months. In addition, significant stem cell survival was found at 1 and 4 months post-irradiation and transplanted cells showed migration to the SGZ and signs of neuronal differentiation [99]. While these findings suggest further investigation is warranted there are multiple complex scientific and ethical issues to navigate before this technology will enter the clinical arena [100].

\section{Conflict of Interest}

Mark G. Shaw declares that he has no conflict of interest.

David L. Ball has board membership with Boehringer-Ingelheim, Pfizer, and Lilly Oncology and received payment for the development of educational presentations from Lilly Oncology and Pfizer.

\section{Human and Animal Rights and Informed Consent}

This article does not contain any studies with human or animal subjects performed by any of the authors. 


\section{References and Recommended Reading}

Papers of particular interest, published recently, have been highlighted as:

- Of importance

$\bullet \quad$ Of major importance

1. U.S. Cancer Statistics Working Group. United States Cancer Statistics: 1999-2009 Incidence and Mortality Web-based Report. Available at http://www.cdc.gov/cancer/lung/statistics/. Accessed July 2013. 2. Barnholtz-Sloan JS, Sloan AE, Davis FG, Vigneau FD, Lai P, Sawaya RE. Incidence proportions of brain metastases in patients diagnosed (1973 to 2001) in the Metropolitan Detroit Cancer Surveillance System. Journal of clinical oncology : official journal of the American Society of Clinical Oncology. 2004;22(14):2865-72. doi:10.1200/JCO.2004.12.149.

3. Schouten LJ, Rutten J, Huveneers HA, Twijnstra A. Incidence of brain metastases in a cohort of patients with carcinoma of the breast, colon, kidney, and lung and melanoma. Cancer. 2002;94(10):2698-705.

4. Nugent JL, Bunn PA, Jr., Matthews MJ, Ihde DC, Cohen MH, Gazdar A et al. CNS metastases in small cell bronchogenic carcinoma: increasing frequency and changing pattern with lengthening survival. Cancer. 1979;44(5):1885-93.

5. Shi AA, Digumarthy SR, Temel JS, Halpern EF, Kuester LB, Aquino SL. Does initial staging or tumor histology better identify asymptomatic brain metastases in patients with non-small cell lung cancer? Journal of thoracic oncology : official publication of the International Association for the Study of Lung Cancer. 2006;1(3):205-10.

6. Smedby KE, Brandt L, Backlund ML, Blomqvist P. Brain metastases admissions in Sweden between 1987 and 2006. British journal of cancer. 2009;101(11):1919-24. doi:10.1038/sj.bjc.6605373.

7. Hirsh V. Systemic therapies in metastatic non-small-cell lung cancer with emphasis on targeted therapies: the rational approach. Current oncology. 2010;17(2):13-23.

8. Zimm S, Wampler GL, Stablein D, Hazra T, Young HF. Intracerebral metastases in solid-tumor patients: natural history and results of treatment. Cancer. 1981;48(2):38494.

9. Posner JB. Management of central nervous system metastases. Seminars in oncology. 1977;4(1):81-91.

10. Sheline GE, Wara WM, Smith V. Therapeutic irradiation and brain injury. International journal of radiation oncology, biology, physics. 1980;6(9):1215-28. 11. Tofilon PJ, Fike JR. The radioresponse of the central nervous system: a dynamic process. Radiation research. 2000;153(4):357-70.

12. Crossen JR, Garwood D, Glatstein E, Neuwelt EA. Neurobehavioral sequelae of cranial irradiation in adults: a review of radiation-induced encephalopathy. Journal of clinical oncology : official journal of the American Society of Clinical Oncology. 1994;12(3):627-42.

13. DeAngelis LM, Delattre JY, Posner JB. Radiation-induced dementia in patients cured of brain metastases. Neurology. 1989;39(6):789-96.

14. Aoyama H, Tago M, Kato N, Toyoda T, Kenjyo M, Hirota S et al. Neurocognitive function of patients with brain metastasis who received either whole brain radiotherapy plus stereotactic radiosurgery or radiosurgery alone. International journal 
of radiation oncology, biology, physics. 2007;68(5):1388-95.

doi:10.1016/j.ijrobp.2007.03.048.

15. Meyers CA, Brown PD. Role and relevance of neurocognitive assessment in clinical trials of patients with CNS tumors. Journal of clinical oncology : official journal of the American Society of Clinical Oncology. 2006;24(8):1305-9. doi:10.1200/JCO.2005.04.6086.

16. Gondi V, Paulus R, Bruner DW, Meyers CA, Gore EM, Wolfson A et al. Decline in tested and self-reported cognitive functioning after prophylactic cranial irradiation for lung cancer: pooled secondary analysis of radiation therapy oncology group randomized trials 0212 and 0214 . International journal of radiation oncology, biology, physics. 2013;86(4):656-64. doi:10.1016/j.ijrobp.2013.02.033.

17. Meyers CA, Wefel JS. The use of the mini-mental state examination to assess cognitive functioning in cancer trials: no ifs, ands, buts, or sensitivity. Journal of clinical oncology : official journal of the American Society of Clinical Oncology. 2003;21(19):3557-8. doi:10.1200/JCO.2003.07.080.

18. Liu R, Page M, Solheim K, Fox S, Chang SM. Quality of life in adults with brain tumors: current knowledge and future directions. Neuro-oncology. 2009;11(3):330-9. doi:10.1215/15228517-2008-093.

19. Scoccianti S, Detti B, Cipressi S, Iannalfi A, Franzese C, Biti G. Changes in neurocognitive functioning and quality of life in adult patients with brain tumors treated with radiotherapy. Journal of neuro-oncology. 2012;108(2):291-308. doi:10.1007/s11060-012-0821-8.

20. Tallet AV, Azria D, Barlesi F, Spano JP, Carpentier AF, Goncalves A et al. Neurocognitive function impairment after whole brain radiotherapy for brain metastases: actual assessment. Radiation oncology. 2012;7:77. doi:10.1186/1748717X-7-77.

* This concise paper is a review of current literature on radiation induced neurocognitive impairment with an exploration of different assessment techniques. The paper also explores the differences between therapeutic and prophylactic cranial irradiation.

21. Regine WF, Scott C, Murray K, Curran W. Neurocognitive outcome in brain metastases patients treated with accelerated-fractionation vs. acceleratedhyperfractionated radiotherapy: an analysis from Radiation Therapy Oncology Group Study 91-04. International journal of radiation oncology, biology, physics. 2001;51(3):711-7.

22. Gregor A, Cull A, Stephens RJ, Kirkpatrick JA, Yarnold JR, Girling DJ et al. Prophylactic cranial irradiation is indicated following complete response to induction therapy in small cell lung cancer: results of a multicentre randomised trial. United Kingdom Coordinating Committee for Cancer Research (UKCCCR) and the European Organization for Research and Treatment of Cancer (EORTC). European journal of cancer. 1997;33(11):1752-8.

23. Komaki R, Meyers CA, Shin DM, Garden AS, Byrne K, Nickens JA et al. Evaluation of cognitive function in patients with limited small cell lung cancer prior to and shortly following prophylactic cranial irradiation. International journal of radiation oncology, biology, physics. 1995;33(1):179-82. doi:10.1016/03603016(95)00026-U.

24. Collins B, Mackenzie J, Stewart A, Bielajew C, Verma S. Cognitive effects of hormonal therapy in early stage breast cancer patients: a prospective study. Psychooncology. 2009;18(8):811-21. doi:10.1002/pon.1453. 
25. Hodgson KD, Hutchinson AD, Wilson CJ, Nettelbeck T. A meta-analysis of the effects of chemotherapy on cognition in patients with cancer. Cancer treatment reviews. 2013;39(3):297-304. doi:10.1016/j.ctrv.2012.11.001.

26. Newcomer JW, Craft S, Hershey T, Askins K, Bardgett ME. Glucocorticoidinduced impairment in declarative memory performance in adult humans. The Journal of neuroscience : the official journal of the Society for Neuroscience.

1994;14(4):2047-53.

27. Zacny JP, Gutierrez S. Characterizing the subjective, psychomotor, and physiological effects of oral oxycodone in non-drug-abusing volunteers. Psychopharmacology. 2003;170(3):242-54. doi:10.1007/s00213-003-1540-9.

28. Keime-Guibert F, Napolitano M, Delattre JY. Neurological complications of radiotherapy and chemotherapy. Journal of neurology. 1998;245(11):695-708.

29. Soussain C, Ricard D, Fike JR, Mazeron JJ, Psimaras D, Delattre JY. CNS complications of radiotherapy and chemotherapy. Lancet. 2009;374(9701):1639-51. doi:10.1016/S0140-6736(09)61299-X.

* This paper describes in great detail the treatment induced neurological complications of radiotherapy, chemotherapy and combined treatment and the pathophysiological basis of these injuries.

30. Belka C, Budach W, Kortmann RD, Bamberg M. Radiation induced CNS toxicity--molecular and cellular mechanisms. British journal of cancer. 2001;85(9):1233-9. doi:10.1054/bjoc.2001.2100.

31. Greene-Schloesser D, Robbins ME, Peiffer AM, Shaw EG, Wheeler KT, Chan MD. Radiation-induced brain injury: A review. Frontiers in oncology. 2012;2:73. doi:10.3389/fonc.2012.00073.

** This review provides an excellent coverage of the theories of radiation induced brain injury and the pathophysiological mechanisms behind injury. Potential targets for ameliorating injury are discussed.

32. Arriagada R, Le Chevalier T, Borie F, Riviere A, Chomy P, Monnet I et al. Prophylactic cranial irradiation for patients with small-cell lung cancer in complete remission. Journal of the National Cancer Institute. 1995;87(3):183-90.

33. Sun A, Bae K, Gore EM, Movsas B, Wong SJ, Meyers CA et al. Phase III trial of prophylactic cranial irradiation compared with observation in patients with locally advanced non-small-cell lung cancer: neurocognitive and quality-of-life analysis. Journal of clinical oncology : official journal of the American Society of Clinical Oncology. 2011;29(3):279-86. doi:10.1200/JCO.2010.29.6053.

34. Le Pechoux C, Laplanche A, Faivre-Finn C, Ciuleanu T, Wanders R, Lerouge D et al. Clinical neurological outcome and quality of life among patients with limited small-cell cancer treated with two different doses of prophylactic cranial irradiation in the intergroup phase III trial (PCI99-01, EORTC 22003-08004, RTOG 0212 and IFCT 99-01). Annals of oncology : official journal of the European Society for Medical Oncology / ESMO. 2011;22(5):1154-63. doi:10.1093/annonc/mdq576. 35. Wolfson AH, Bae K, Komaki R, Meyers C, Movsas B, Le Pechoux C et al. Primary analysis of a phase II randomized trial Radiation Therapy Oncology Group (RTOG) 0212: impact of different total doses and schedules of prophylactic cranial irradiation on chronic neurotoxicity and quality of life for patients with limiteddisease small-cell lung cancer. International journal of radiation oncology, biology, physics. 2011;81(1):77-84. doi:10.1016/j.ijrobp.2010.05.013. 
36. Ball DL, Matthews JP. Prophylactic Cranial Irradiation: More Questions Than Answers. Seminars in radiation oncology. 1995;5(1):61-8. doi:10.1054/SRAO00500061.

37. Tsao MN, Lloyd N, Wong RK, Chow E, Rakovitch E, Laperriere N et al. Whole brain radiotherapy for the treatment of newly diagnosed multiple brain metastases. Cochrane database of systematic reviews. 2012;4:CD003869.

doi:10.1002/14651858.CD003869.pub3.

38. Young DF, Posner JB, Chu F, Nisce L. Rapid-course radiation therapy of cerebral metastases: results and complications. Cancer. 1974;34(4):1069-76.

39. Hindo WA, DeTrana FA, 3rd, Lee MS, Hendrickson FR. Large dose increment irradiation in treatment of cerebral metastases. Cancer. 1970;26(1):138-41.

40. Eriksson PS, Perfilieva E, Bjork-Eriksson T, Alborn AM, Nordborg C, Peterson DA et al. Neurogenesis in the adult human hippocampus. Nature medicine. 1998;4(11):1313-7. doi:10.1038/3305.

41. Colicos MA, Dash PK. Apoptotic morphology of dentate gyrus granule cells following experimental cortical impact injury in rats: possible role in spatial memory deficits. Brain research. 1996;739(1-2):120-31.

42. Raber J, Rola R, LeFevour A, Morhardt D, Curley J, Mizumatsu S et al.

Radiation-induced cognitive impairments are associated with changes in indicators of hippocampal neurogenesis. Radiation research. 2004;162(1):39-47.

43. Rola R, Raber J, Rizk A, Otsuka S, VandenBerg SR, Morhardt DR et al.

Radiation-induced impairment of hippocampal neurogenesis is associated with cognitive deficits in young mice. Experimental neurology. 2004;188(2):316-30. doi:10.1016/j.expneurol.2004.05.005.

44. Wan JF, Zhang SJ, Wang L, Zhao KL. Implications for preserving neural stem cells in whole brain radiotherapy and prophylactic cranial irradiation: a review of 2270 metastases in 488 patients. Journal of radiation research. 2013;54(2):285-91. doi:10.1093/jrr/rrs085.

45. Gondi V, Tome WA, Marsh J, Struck A, Ghia A, Turian JV et al. Estimated risk of perihippocampal disease progression after hippocampal avoidance during wholebrain radiotherapy: safety profile for RTOG 0933. Radiotherapy and oncology : journal of the European Society for Therapeutic Radiology and Oncology. 2010;95(3):327-31. doi:10.1016/j.radonc.2010.02.030.

46. Mehta MP. Radiation Therapy Oncology Group: RTOG 0933 Protocol. Available at http://www.rtog.org/ClinicalTrials/ProtocolTable/StudyDetails.aspx?study=0933 Accessed July, 2013.

* This article, the RTOG 0933 protocol, describes the rationale behind hippocampal sparing radiation and provides an excellent stepwise guide on how to contour and plan for hippocampal sparing radiotherapy.

47. Gondi V, Hermann BP, Mehta MP, Tome WA. Hippocampal dosimetry predicts neurocognitive function impairment after fractionated stereotactic radiotherapy for benign or low-grade adult brain tumors. International journal of radiation oncology, biology, physics. 2013;85(2):348-54. doi:10.1016/j.ijrobp.2012.11.031.

48. Mizumatsu S, Monje ML, Morhardt DR, Rola R, Palmer TD, Fike JR. Extreme sensitivity of adult neurogenesis to low doses of $\mathrm{X}$-irradiation. Cancer research. 2003;63(14):4021-7.

49. Barani IJ, Benedict SH, Lin PS. Neural stem cells: implications for the conventional radiotherapy of central nervous system malignancies. International 
journal of radiation oncology, biology, physics. 2007;68(2):324-33.

doi:10.1016/j.ijrobp.2007.01.033.

50. Marsh JC, Gielda BT, Herskovic AM, Wendt JA, Turian JV. Sparing of the hippocampus and limbic circuit during whole brain radiation therapy: A dosimetric study using helical tomotherapy. Journal of medical imaging and radiation oncology. 2010;54(4):375-82. doi:10.1111/j.1754-9485.2010.02184.x.

51. Marsh JC, Gielda BT, Herskovic AM, Abrams RA. Cognitive Sparing during the Administration of Whole Brain Radiotherapy and Prophylactic Cranial Irradiation:

Current Concepts and Approaches. Journal of oncology. 2010;2010:198208. doi: $10.1155 / 2010 / 198208$.

* This paper describes the mechanisms of CNS toxicity and explores the role of hippocampal sparing, limbic circuit sparing and neural stem cell sparing radiotherapy.

52. Barani IJ, Larson DA, Berger MS. Future directions in treatment of brain metastases. Surgical neurology international. 2013;4(Suppl 4):S220-30. doi:10.4103/2152-7806.111299.

* An excellent review of recent studies investigating the role of WBRT and SRS with a focus on multiple brain metastases and projections for future treatment regimes.

53. Aoyama H, Shirato H, Tago M, Nakagawa K, Toyoda T, Hatano K et al. Stereotactic radiosurgery plus whole-brain radiation therapy vs stereotactic radiosurgery alone for treatment of brain metastases: a randomized controlled trial. JAMA : the journal of the American Medical Association. 2006;295(21):2483-91. doi:10.1001/jama.295.21.2483.

54. Chang EL, Wefel JS, Hess KR, Allen PK, Lang FF, Kornguth DG et al. Neurocognition in patients with brain metastases treated with radiosurgery or radiosurgery plus whole-brain irradiation: a randomised controlled trial. The lancet oncology. 2009;10(11):1037-44. doi:10.1016/S1470-2045(09)70263-3.

** The only phase III RCT of SRS versus SRS with WBRT with a primary endpoint of neurocognitive function. The study was closed early according to early stopping rules on the basis that there was a high probability $(96 \%)$ that patients randomly assigned to receive SRS plus WBRT were significantly more likely to show a decline in learning and memory function.

55. Kocher M, Soffietti R, Abacioglu U, Villa S, Fauchon F, Baumert BG et al. Adjuvant whole-brain radiotherapy versus observation after radiosurgery or surgical resection of one to three cerebral metastases: results of the EORTC 22952-26001 study. Journal of clinical oncology : official journal of the American Society of Clinical Oncology. 2011;29(2):134-41. doi:10.1200/JCO.2010.30.1655.

** This paper reports on the EORTC phase III RCT of WBRT versus observation after local therapy for 1-3 brain metastases. This large 359 patient trial provides a definitive statement on the impact of WBRT after local therapy.

56. Patchell RA, Tibbs PA, Regine WF, Dempsey RJ, Mohiuddin M, Kryscio RJ et al. Postoperative radiotherapy in the treatment of single metastases to the brain: a randomized trial. JAMA : the journal of the American Medical Association. 1998;280(17):1485-9.

57. Mahmood U, Kwok Y, Regine WF, Patchell RA. Whole-brain irradiation for patients with brain metastases: still the standard of care. The lancet oncology. 2010;11(3):221-2; author reply 3. doi:10.1016/S1470-2045(09)70389-4. 
58. Weiss SE, Kelly PJ. Neurocognitive function after WBRT plus SRS or SRS alone. The lancet oncology. 2010;11(3):220-1. doi:10.1016/S1470-2045(09)70387-0. 59. Soffietti R, Kocher M, Abacioglu UM, Villa S, Fauchon F, Baumert BG et al. A European Organisation for Research and Treatment of Cancer phase III trial of adjuvant whole-brain radiotherapy versus observation in patients with one to three brain metastases from solid tumors after surgical resection or radiosurgery: quality-oflife results. Journal of clinical oncology : official journal of the American Society of Clinical Oncology. 2013;31(1):65-72. doi:10.1200/JCO.2011.41.0639.

** This paper reports the QOL outcomes from [55]. It is the first such analysis and reveals a generally lower, albeit mild and transitory, change in QOL after WBRT.

60. Li J, Bentzen SM, Renschler M, Mehta MP. Regression after whole-brain radiation therapy for brain metastases correlates with survival and improved neurocognitive function. Journal of clinical oncology : official journal of the American Society of Clinical Oncology. 2007;25(10):1260-6.

doi:10.1200/JCO.2006.09.2536.

61. Brown WR, Blair RM, Moody DM, Thore CR, Ahmed S, Robbins ME et al. Capillary loss precedes the cognitive impairment induced by fractionated whole-brain irradiation: a potential rat model of vascular dementia. Journal of the neurological sciences. 2007;257(1-2):67-71. doi:10.1016/j.jns.2007.01.014.

62. Wilcock G, Mobius HJ, Stoffler A, group MMM. A double-blind, placebocontrolled multicentre study of memantine in mild to moderate vascular dementia (MMM500). International clinical psychopharmacology. 2002;17(6):297-305.

63. Tsien JZ. Building a brainier mouse. Scientific American. 2000;282(4):62-8.

64. Brown PD, Shook S, Laack NN, Wefel JS, Choucair A, Suh JH et al. Memantine for the Prevention of Cognitive Dysfunction in Patients Receiving Whole-brain Radiation Therapy (WBRT): First Report of RTOG 0614, a Placebo-controlled, Double-blind, Randomized Trial. International journal of radiation oncology, biology, physics. 2012;84(3):S1-S2.

65. Shaw EG, Rosdhal R, D'Agostino RB, Jr., Lovato J, Naughton MJ, Robbins ME et al. Phase II study of donepezil in irradiated brain tumor patients: effect on cognitive function, mood, and quality of life. Journal of clinical oncology : official journal of the American Society of Clinical Oncology. 2006;24(9):1415-20.

doi:10.1200/JCO.2005.03.3001.

66. Rapp SR, Case D, Peiffer A, Naughton MJ, Stieber VW, Bayer GK et al. Phase III randomized, double-blind, placebo-controlled trial of donepezil in irradiated brain tumor survivors. 2013 ASCO Annual Meeting. Oral Abstract Session, Central Nervous System Tumours. J Clin Oncol 31, 2013 (suppl; abstr 2006).

67. Nonaka S, Chuang DM. Neuroprotective effects of chronic lithium on focal cerebral ischemia in rats. Neuroreport. 1998;9(9):2081-4.

68. Rowe MK, Chuang DM. Lithium neuroprotection: molecular mechanisms and clinical implications. Expert reviews in molecular medicine. 2004;6(21):1-18. doi:10.1017/S1462399404008385.

69. Yazlovitskaya EM, Edwards E, Thotala D, Fu A, Osusky KL, Whetsell WO, Jr. et al. Lithium treatment prevents neurocognitive deficit resulting from cranial irradiation. Cancer research. 2006;66(23):11179-86. doi:10.1158/0008-5472.CAN-062740 .

70. Khasraw M, Ashley D, Wheeler G, Berk M. Using lithium as a neuroprotective agent in patients with cancer. BMC medicine. 2012;10:131. doi:10.1186/1741-7015$10-131$. 
*This summary article describes the role of Lithium in neurocognitive dysfunction and its potential role in radiation neuroprotection.

71. Foland LC, Altshuler LL, Sugar CA, Lee AD, Leow AD, Townsend J et al. Increased volume of the amygdala and hippocampus in bipolar patients treated with lithium. Neuroreport. 2008;19(2):221-4. doi:10.1097/WNR.0b013e3282f48108. 72. Chen G, Rajkowska G, Du F, Seraji-Bozorgzad N, Manji HK. Enhancement of hippocampal neurogenesis by lithium. Journal of neurochemistry. 2000;75(4):172934.

73. Huo K, Sun Y, Li H, Du X, Wang X, Karlsson N et al. Lithium reduced neural progenitor apoptosis in the hippocampus and ameliorated functional deficits after irradiation to the immature mouse brain. Molecular and cellular neurosciences. 2012;51(1-2):32-42. doi:10.1016/j.mcn.2012.07.002.

74. Barwon Health, Deakin University, Peter MacCallum Cancer Centre; Australia. A Feasibility Trial Using Lithium As A Neuroprotective Agent In Patients Undergoing Prophylactic Cranial Irradiation For Small Cell Lung Cancer (TULIP). Available at http://clinicaltrials.gov/ct2/show/NCT01486459 NLM identifier: NCT01486459. Accessed July, 2013.

75. Paul M, Poyan Mehr A, Kreutz R. Physiology of local renin-angiotensin systems. Physiological reviews. 2006;86(3):747-803. doi:10.1152/physrev.00036.2005.

76. Ghosh SN, Zhang R, Fish BL, Semenenko VA, Li XA, Moulder JE et al. ReninAngiotensin system suppression mitigates experimental radiation pneumonitis. International journal of radiation oncology, biology, physics. 2009;75(5):1528-36. doi:10.1016/j.ijrobp.2009.07.1743.

77. Moulder JE, Cohen EP, Fish BL. Captopril and losartan for mitigation of renal injury caused by single-dose total-body irradiation. Radiation research.

2011;175(1):29-36. doi:10.1667/RR2400.1.

78. George AJ, Thomas WG, Hannan RD. The renin-angiotensin system and cancer: old dog, new tricks. Nature reviews Cancer. 2010;10(11):745-59.

doi:10.1038/nrc2945.

79. Robbins ME, Zhao W, Garcia-Espinosa MA, Diz DI. Renin-angiotensin system blockers and modulation of radiation-induced brain injury. Current drug targets. 2010;11(11):1413-22.

*This comprehensive paper describes the role of RAS in the brain and the potential role of RAS blockers in amelioration of radiation induced brain injury.

80. Kim JH, Brown SL, Kolozsvary A, Jenrow KA, Ryu S, Rosenblum ML et al. Modification of radiation injury by ramipril, inhibitor of angiotensin-converting enzyme, on optic neuropathy in the rat. Radiation research. 2004;161(2):137-42. 81. Robbins ME, Payne V, Tommasi E, Diz DI, Hsu FC, Brown WR et al. The AT1 receptor antagonist, L-158,809, prevents or ameliorates fractionated whole-brain irradiation-induced cognitive impairment. International journal of radiation oncology, biology, physics. 2009;73(2):499-505. doi:10.1016/j.ijrobp.2008.09.058.

82. Conner KR, Forbes ME, Lee WH, Lee YW, Riddle DR. AT1 receptor antagonism does not influence early radiation-induced changes in microglial activation or neurogenesis in the normal rat brain. Radiation research. 2011;176(1):71-83. 83. Lee TC, Greene-Schloesser D, Payne V, Diz DI, Hsu FC, Kooshki M et al. Chronic administration of the angiotensin-converting enzyme inhibitor, ramipril, prevents fractionated whole-brain irradiation-induced perirhinal cortex-dependent cognitive impairment. Radiation research. 2012;178(1):46-56. 
84. Jenrow KA, Liu J, Brown SL, Kolozsvary A, Lapanowski K, Kim JH. Combined atorvastatin and ramipril mitigate radiation-induced impairment of dentate gyrus neurogenesis. Journal of neuro-oncology. 2011;101(3):449-56. doi:10.1007/s11060010-0282-X.

85. Bordet R, Ouk T, Petrault O, Gele P, Gautier S, Laprais M et al. PPAR: a new pharmacological target for neuroprotection in stroke and neurodegenerative diseases. Biochemical Society transactions. 2006;34(Pt 6):1341-6. doi:10.1042/BST0341341. 86. Ramanan S, Kooshki M, Zhao W, Hsu FC, Riddle DR, Robbins ME. The PPARalpha agonist fenofibrate preserves hippocampal neurogenesis and inhibits microglial activation after whole-brain irradiation. International journal of radiation oncology, biology, physics. 2009;75(3):870-7. doi:10.1016/j.ijrobp.2009.06.059. 87. Schnegg CI, Greene-Schloesser D, Kooshki M, Payne VS, Hsu FC, Robbins ME. The PPARdelta agonist GW0742 inhibits neuroinflammation, but does not restore neurogenesis or prevent early delayed hippocampal-dependent cognitive impairment after whole-brain irradiation. Free radical biology \& medicine. 2013;61C:1-9. doi:10.1016/j.freeradbiomed.2013.03.002.

88. Zhao W, Payne V, Tommasi E, Diz DI, Hsu FC, Robbins ME. Administration of the peroxisomal proliferator-activated receptor gamma agonist pioglitazone during fractionated brain irradiation prevents radiation-induced cognitive impairment. International journal of radiation oncology, biology, physics. 2007;67(1):6-9. doi:10.1016/j.ijrobp.2006.09.036.

89. Wake Forest University. Pioglitazone Hydrochloride in preventing radiationinduced cognitive dysfunction in treating patients with brain tumors. Available from: http://clinicaltrials.gov/ct2/show/NCT01151670 NLM identifier: NCT0115670. Accessed July, 2013.

90. Stessin AM, Gursel DB, Schwartz A, Parashar B, Kulidzhanov FG, Sabbas AM et al. FTY720, sphingosine 1-phosphate receptor modulator, selectively radioprotects hippocampal neural stem cells. Neuroscience letters. 2012;516(2):253-8. doi:10.1016/j.neulet.2012.04.004.

91. Zorrilla Zubilete MA, Guelman LR, Maur DG, Caceres LG, Rios H, Zieher LM et al. Partial neuroprotection by $17-\beta$-estradiol in neonatal gamma-irradiated rat cerebellum. Neurochemistry international. 2011;58(3):273-80.

92. Mehrotra S, Pecaut MJ, Gridley DS. Analysis of minocycline as a countermeasure against acute radiation syndrome. In vivo. 2012;26(5):743-58.

93. Oh SB, Park HR, Jang YJ, Choi SY, Son TG, Lee J. Baicalein attenuates impaired hippocampal neurogenesis and the neurocognitive deficits induced by gamma-ray radiation. British journal of pharmacology. 2013;168(2):421-31. doi:10.1111/j.14765381.2012.02142.x.

94. Attia A, Rapp SR, Case LD, D'Agostino R, Lesser G, Naughton M et al. Phase II study of Ginkgo biloba in irradiated brain tumor patients: effect on cognitive function, quality of life, and mood. Journal of neuro-oncology. 2012;109(2):357-63.

doi:10.1007/s11060-012-0901-9.

95. Said UZ, Saada HN, Abd-Alla MS, Elsayed ME, Amin AM. Hesperidin attenuates brain biochemical changes of irradiated rats. International journal of radiation biology. 2012;88(8):613-8. doi:10.3109/09553002.2012.694008.

96. Xin N, Li YJ, Li X, Wang X, Li Y, Zhang X et al. Dragon's blood may have radioprotective effects in radiation-induced rat brain injury. Radiation research. 2012;178(1):75-85.

97. Liu JL, Tian DS, Li ZW, Qu WS, Zhan Y, Xie MJ et al. Tamoxifen alleviates irradiation-induced brain injury by attenuating microglial inflammatory response in 
vitro and in vivo. Brain research. 2010;1316:101-11.

doi:10.1016/j.brainres.2009.12.055.

98. Wong-Goodrich SJ, Pfau ML, Flores CT, Fraser JA, Williams CL, Jones LW.

Voluntary running prevents progressive memory decline and increases adult

hippocampal neurogenesis and growth factor expression after whole-brain irradiation.

Cancer research. 2010;70(22):9329-38. doi:10.1158/0008-5472.CAN-10-1854.

99. Acharya MM, Christie LA, Lan ML, Donovan PJ, Cotman CW, Fike JR et al.

Rescue of radiation-induced cognitive impairment through cranial transplantation of

human embryonic stem cells. Proceedings of the National Academy of Sciences of the United States of America. 2009;106(45):19150-5. doi:10.1073/pnas.0909293106.

100. Daley GQ, Ahrlund Richter L, Auerbach JM, Benvenisty N, Charo RA, Chen G

et al. Ethics. The ISSCR guidelines for human embryonic stem cell research. Science.

2007;315(5812):603-4. doi:10.1126/science.1139337. 


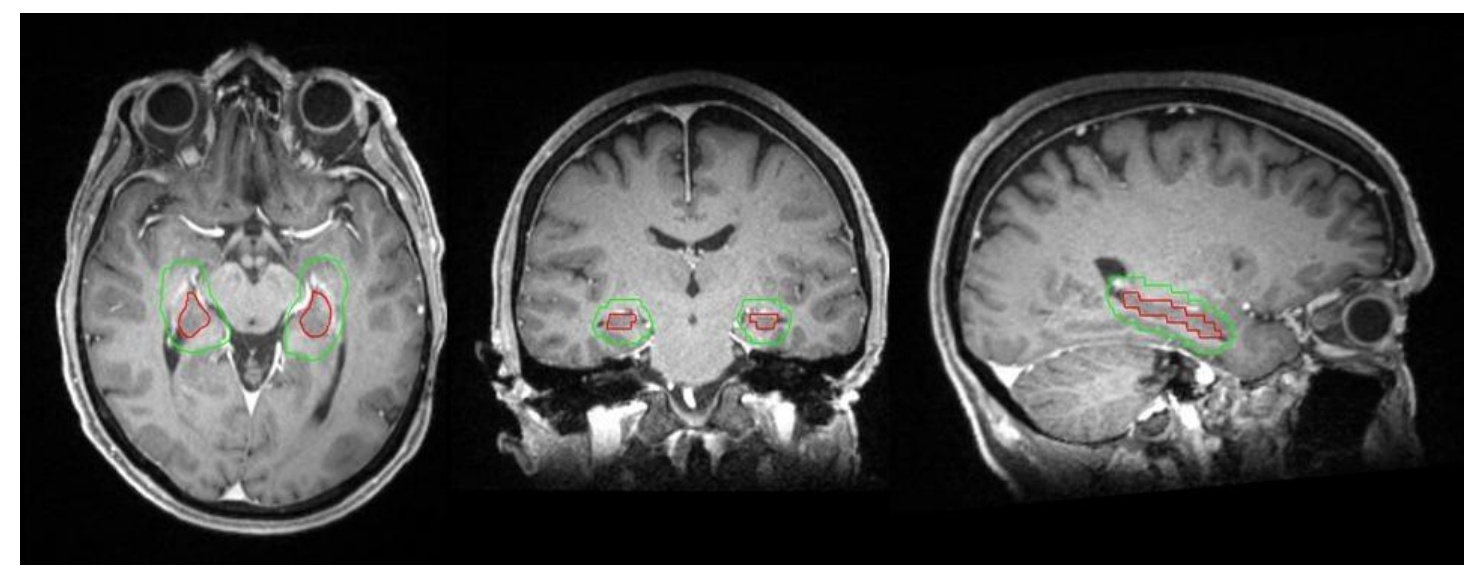

